José Francisco Rezek, doutor em direito, professor de direito na Universidade de Brasília, Subprocurador-Geral da República e Assessor da Chefia do Gabinete Civil da Presidência da República.

\title{
Limites constitucionais da liberdade de trabalho
}

1. Parecer produzido nos autos da Representação n? 1056, ainda não julgada pelo Supremo Tribunal Federal. O relator do feito é o Ministro Décio Miranda. Como assistente do Procurador-geral da República, na argüição de inconstitucionalidade dos dispositivos de lei em debate, figura a Sociedade Brasileira de Medicina Física e Reabilitação. Como assistente do legislador responsável pela edição das mesmas normas (no caso, o Congresso Nacional e o Presidente da República), figura o Conselho Federal de Fisioterapia e Terapia Ocupacional.

A norma constitucional operante, no caso, como parâmetro, é aquela que, dentro do rol dos direitos e garantias individuais, vem, desde a Carta Polltica do Império do Brasil, assegurando. sob certas ressalvas, a liberdade de ofício ou opçăo laboral. Essa regra evoluiu, entre nós, do modo seguinte:

- Constituição de 1824, art. 179: "XXIV - Nenhum gênero de trabalho, de cultura, indústria, ou comércio pode ser proibido uma vez que não se oponha aos costumes públicos, à segurança, e saúde dos Cidadãos; XXV - Ficam abolidas as Corporações de Ofícios, seus Juízes, Escrivães, e Mestres.'

- Constituição de 1891, art.
Representação por inconstitucionalidade ${ }^{1}$.

Dispositivos de lei federal que delimitam a área de trabalho privativa de fisioterapeutas e terapeutas ocupacionais; e que impõem às empresas do setor o registro em órgão de fiscalização competente. Distinção entre essas especializações profissionais e a medicina fisiátrica ou psiquiátrica, apurável à luz do sistema universitário.

\section{Representação improcedente.}

Reservando-se para um pronunciamento final sobre o mérito, o Procurador-geral da República argüiu ante essa alta Corte a inconstitucionalidade dos seguintes dispositivos da legislação federal:

Decreto-lei n? 938, de 13 de outubro de 1969:

"Art. 3. - É atividade privativa do fisioterapeuta executar métodos e técnicas fisioterápicas com a finalidade de restaurar, desenvolver e conservar a capacidade física do paciente".

"Art. 4. - É atividade privativa do terapeuta ocupacional executar métodos e técnicas terapêuticas e recreacionais com a finalidade de restaurar, desenvolver e conservar a capacidade mental do paciente".

Lei n: 6. 316, de 17 de dezembro de 1975:

"Art. 12 (...)

Parágrafo único: É obrigatório o registro nos conselhos regionais das empresas cujas finalidades estejam ligadas à fisioterapia ou terapia ocupacional na forma estabelecida em Regulamento. 
72: "§ 24: E garantido o livro exercício de qualquer profissão moral, intelectual e industrial".

- Constituição de 1934, art. 113: "13: E livre o exercício de qualquer profissão, observadas as condições de capacidade técnica e outras que a lei estabelecer, ditadas pelo interesse públi$\mathrm{CO}^{\prime \prime}$.

- Constituição de 1937, art. 122: (sic) "8: A liberdade de escoIha de profissão ou do gênero de trabalho, indústria ou comércio, observadas as condições de capacidade e as restrições impostas pelo bem público, nos termos da lei"

- Constituição de 1946, art. 141: "§ 14: É livre o exercício de qualquer profissão, observadas as condições de capacidade que a lei estabelecer."

- Constituição de 1967,"art. 150, e de 1969, art. 153: "§ 23: E livre o exercício de qualquer trabalho, ofício ou profissão, observadas as condiç̃oes de capacida de que a lei estabelecer."

Nos últimos anos, o mais destacado precedente relacionado com o $\$ 23$ do rol de garantias foi a Representação n: 930, em que o Supremo Tribunal Federal derrubou por inconstitucionalidade material a Lei $n^{\circ}$ 4.116/62, que regulamentara a profissão de corretor de imóveis. A maioria adotou o ponto de vista que o Ministro Rodrigues Alckmin assumira já quando desembargador em Såo Paulo, e que, nessa ocasião, desenvolveu com particular alento. Aqui um excerto expressivo de seu voto: "Postos estes princípios - os de que a liberdade de exercício da profissão é constitucionalmente assegurada no Brasil, embora limitável por lei ordinária; mas que a lei ordinária pode exigir somente as condiçøes de capacidade reclamadas pelo interesse superior da coletividade; e que ao judiciário cabe apurar se a regulamentação é, ou não, legitima - merece exame. agora, o impugnado art. $7^{\circ}$ da Lei 4.116. Começa essa lei por estabelecer o regulamento de uma profissão de corretor de imóveis, profissão que, consoante o critério proposto por Sampaio Dória, não pode ser regulamentada sob o aspecto de capacidade técnica, por dupla razão. Primeiro, porque essa atividade, mesmo exercida por inepto, nåo prejudicará diretamente a direito de terceiro. Quem não conseguir obter comprador para
A representação por inconstitucionalidade atendeu a quanto fora postulado pela Sociedade Brasileira de Medicina Física e Reabilitação, e pelo Conselho Federal de Medicina. É certo que o objetivo dessas duas entidades, e sobretudo da primeira, era mais amplo, pois consistia, ademais, em ver proscritos alguns extratos de lei que nada pro bem, expressa ou implicitamente, aos médicos, limitandose a permitir aos fisioterapeutas e terapeutas ocupacionais certas atividades para as quais, ao ver daqueles, estes não se encontram dotados de competência, no sentido técnico-científico. A primeira tarefa do Ministério Público neste caso foi, pois, a de repelir a tese de que exista uma questão constitucional na aventada - pelos postulantes originais - generosidade do legislador ordinário para com aquelas duas outras categorias. A questão constitucional só reponta, com a verossimilhança necessária à argüição do vício ante essa Corte, na medida em que se admita, em princípio, que certos dispositivos legais poderiam estar tolhendo a liberdade de trabalho do médico, sem que se possa dizê-lo incapaz para aquele mister ali reservado a outrem, com exclusividade (Constituição Federal, art. 153, § 23).

As informações de folhas 82/97 foram preparadas pela Consultoria Jurídica do Ministério do Trabalho. Penso poder sintetizálas, adequadamente, com a transcrição que segue:

"Há que se convir que a privatividade prevista nos questionados arts. $3^{\circ}$ e $44^{\circ}$ do Decreto-lei n. 938/69 precisa ser compatibilizada com os dispositivos constitucionais e legais que asseguram aos médicos a mesma privatividade para o exercício da medicina física. E isso, exatamente, é o que nos parece deva ser considerado no exame de questão aqui aflorada.

A ser considerado que a privatividade de fisioterapeutas ocupacionais excluiria o médico, que sempre exerceu a medicina física, certamente caberia a alegação de inconstitucionalidade, pois afetaria direitos adquiridos deste profissional e também de classe médica, que ficaria obstada da especialização atinente à medicina de recuperação.

A se admitir, por outro lado, que a atividade seria privativa apenas do médico, com a exclusão dos fisioterapeutas e terapeutas ocupacionais, ter-se-ia, igualmente com certeza, a hipótese de inconstitucionalidade, porquanto o direito para executar métodos e técnicas na fisioterapia e terapia ocupacional estes profissionais também o adquiriram através de habilitação em curso de nível superior. Nessa ordem de raciocínio, temos a convicção de que, sem ilegalidade ou inconstitucionalidade, seria possível uma conciliação de interesses, adotando-se como solução o seguinte: "o médico (fisiatra) faz o diagnóstico, indica (e, se achar conveniente, executa) o tratamento, acompanha a sua execução, prescreve, supervisiona, dá alta etc.; o fisioterapeuta e terapeuta-ocupacional executam o tratamento. A privatividade destes não se opõe ao fisiatra" (conforme o item 41 do Parecer da Consultoria Jurídica n. 032/80).

Não terá sido outra a intenção do legislador senão a de permitir o exercício da mesma atividade na área de saúde pelos médicos fi- 
propriedades cuja venda promova, a ninguém mais prejudicará, que a si próprio. Em segundo lugar, porque nåo há requisito de capacidade técnica algum, para exercê-la.

Que diplomas, que aprendizado, que prova de conhecimento se exigem para o exercício dessa profissão? Nenhum é necessário. Logo, à evidência, não se justificaria a regulamentação, sob o aspecto de exigência, pelo bem comum, pelo interesse, de capacidade técnica.

Haverá, acaso ditado pelo bem comum, algum outro requisito de capacidade exigivel aos exercentes dessa profissão? Nenhum. A comum honestidade dos individuos não é requisito profissional e sequer exige, a natureza da atividade, especial idoneidade moral para que possa ser exercida sem risco. Conseqüentemente, o interesse público de forma alguma impôe seja regulamentada a profissã de corretor de imóveis, como não impõe com relação a tantas e tantas atividades profissionais que, por dispensarem maiores conhecimentos técnicos ou aptidões especiais físicas ou morais, também não se regulamentam.

Como justificar-se, assim, a regulamentação? Note-se que não há, na verdade, interesse coletivo algum que a imponha. E o que se conseguiu, com a lei, foi criar uma disfarçada corporação de ofício, a favor dos exercentes da atividade, coisa que a regra constitucional e o regime democrático vigente repelem".

Ficaram vencidos, nesse julgamento, o relator original, Ministro Cordeiro Guerra, e o Ministro Cunha Peixoto, que não davam pela presença do vício de inconstitucionalidade em parte alguma do contexto. Foram também vencidos, mas em parte, os Ministros Bilac Pinto e Xavier de Albuquerque, patrocinando a idéia, desenvolvida em plenário pelo último, de que a regulamentação de um oficio não pode ser inconstitucional em si mesma, senão na medida em que resulte restrito o direito, para qualquer pessoa, de se consagrar a tal ofício, suposto que o mesmo não reclame habilitação em nome do interesse público. Aqui uma consideração vestibular, do voto do Ministro Xavier de Albuquerque: "A meu ver, a regulamentaçăo de determinada atividade, com ou sem a designação formal de profissåo, pode ser útil ao interesse público na medida em que siatras e pelos fisioterapeutas e terapeutas ocupacionais, vez que tanto estes como aqueles estão legal e tecnicamente habilitados.

A interpretação dos arts. 3. e 4. , em pauta, leva a essa conclusão. É que, aos fisioterapeutas e terapeutas ocupacionais é conferida privatividade apenas para executar, parece lógico que a indicação, o diagnóstico, o acompanhamento a alta etc. , deva ser de competência de outro profissional, isto é, do fisiatra. Conseqüentemente, não será compreensível que quem esteja habilitado a tanto, não possa também 'executar', se achar conveniente." (folhas 93/94).

\section{$(\ldots \ldots \ldots \ldots \ldots)$}

"Tudo depende da aplicação daqueles dispositivos. São constitucionais, se a interpretação não for excludente da atividade do médico fisiatra, como, aliás entende esta Consultoria. Contrário senso, são inconstitucionais, se aplicados em prejuízo dos direitos adquiridos daquele profissional". (folhas 95/96).

Com a devida vênia, hesita o Ministério Público em se acomodar à idéia de que tudo possa ficar circunscrito no terreno da interpretação. Os artigos 3. e 4. do Decreto-lei 938/69 são claros na privatividade que estabelece em prol dos fisioterapeutas e terapeutas ocupacionais, sem reservas ou exceções a favor da classe médica. Parece inviável, dessarte, uma solução conciliatória, à base da hermenêutica. Ou o egrégio Tribunal entende válida a privatividade, tal como estabelecida no texto, e desacolhe a representação; ou abona o pensamento da douta Consultoria Jurídica do Ministério do Trabalho, que pugna pela competência concorrente dos graduados em medicina. Nesse último caso, não podendo legislar, ver-se-á o Tribunal na contingência de derrubar, por inconstitucionais em sua forma atual, os arts. 3. e 4. do Decreto-lei 938/69 - ou, quando menos, dentro de cada um deles, o adjetivo pertinente à privatividade - sem prejuízo da perspectiva, aberta ao legislador, de reescrever oportunamente esses textos, ditando, então, a alvitrada "privatividade não oponível à classe médica".

Esta última solução não é a melhor. Sem negar louvores à boa fé que há de ter inspirado a tese da competência concorrente, o Ministério Público entende que a privatividade de que falam os dispositivos em causa não afronta qualquer garantia que a classe médica possa recolher no art. 153 da Carta Republicana; e experimenta, ao mesmo tempo, certa dificuldade em conceber que os médicos fisiatras ou psiquiatras estejam realmente sentido-se cerceados, em seu labor individual, pelas normas que privatizam, respectivamente, a execução: ". . de métodos e técnicas fisioterápicos..." e" ... de métodos e técnicas terapêuticos e recreacionais..."

Na Representação n: 930, também pertinente à liberdade de trabalho garantida pelo art. 153, § 23 da Lei Maior, esse egrégio Tribunal proscreveu a privatização da corretagem imobiliária, por entender, em última análise, que, do ponto de vista da qualificação técnica requerida, negociar com imóveis é tarefa que não difere de negociar com automóveis ou com cereais. Para tanto se exige não mais que honestidade - imposta, por lei, às pessoas em geral - , e, 
contenha elementos capazes de prestigiar os que exercitam, incutindo-Ihes a confiança do povo em geral; mas, nåo the pode bastar tal utilidade quando e onde arrebate ao homem comum, sem que o faça em nome de verdadeiras condiçóes de capacidade, como exige a Constituição, o acesso à respectiva categoria.

Quero dizer que tenho a lei em questão como inconstitucional, acolhendo, em suas linhas gerais, os fundamentos básicos dos votos dos eminentes Ministros Rodrigues Alckmin e Leitão de Abreu, mas nåo lhe estendo a eiva de inconstitucionalidade a todo o corpo de normas. Parece-me que o vício reside apenas naquelas, de suas normas, que induzem, asseguram ou sugeriu a privatividade, a exclusividade do exercício da atividade, aos inscritos nos respectivos Conselhos"

No caso a que este parecer se refere, o Procurador-geral da República foi instado por entidades representativas da classe médica a dar à Representação alcance muito mais amplo. Parecia a essas entidades que o legislador fora abusivamente generoso na avaliação da competência dos fisioterapeutas e terapeutas, ocupacionais, atribuindo-lhes encargos para os quais Ihes falece qualidade técnica, sob a b́tica dos médicos. De pronto, o chefe do Ministério Público deu pela impertinência de semelhante discussão: não pode haver inconstitucionalidade, senão mero erro de política legislativa, quando a lei ordinária liberaliza condiçðes de exercício profissional. A afronta ao $\S 23$ do rol constitucional de garantias somente ocorre quando o legislador atua restritivamente, impedindo pessoas da execuçăo de certo trabalho, sem que esse gesto se apóie no argumento de que para tanto lhes falta capacidade. A Representação, afinal, só colocou em debate aquelas normas que estabelecem, em favor dos fisioterapeutas e terapeutas ocupacionais, uma privatividade que os médicos fisiatras estimam descabida, eis que se consideram, eles próprios, pelo menos tão competentes quanto aqueles outros profissionais para o bom desempenho dos misteres em causa. Como de hábito, o Procurador-geral representou ante o Supremo à só consideração da razoabilidade dessa última tese, reservando-se, porém, para um ulterior pronunciamento, definitivo, sobre o mérito. Este parecer final foi lançado nos autos depois da já agora com vistas ao êxito do empreendimento, algum tino comercial, certa noção do mercado específico, quiçá alguma experiência. O nível de instrução ou de treinamento regular, naquele caso, poderia limitar-se à escolaridade primária. Privatizar semelhante atividade, como entendeu o Tribunal, na trilha do que dissera - ainda como Desembargador em São Paulo - o sempre saudoso Ministro Rodrigues Alckmin, representava uma velada e reprovável restauração das corporações de oflcio.

O caso em exame é substancialmente diverso. Cuidou a lei, aqui, de conferir a necessária privatividade ao exercício de profissões que têm, como pressuposto inarredável, um curso de graduação universitária, completo e específico.

Permito-me dar ênfase ao que isso representa. A instituição de cursos universitários é matéria de âmbito federal, nela se destacando o exercício da competência, seletiva e controladora, de um órgão do mais alto nível, qual seja o Conselho Federal de Educação. Não se criam novos cursos de graduação, neste país, senão quando a área do conhecimento de que se cuida justifica trato autônomo, em nível universitário; e tem estofo quantitativo bastante para preencher um currículo acadêmico, a ser enfrentado, pelo estudante, em tempo nunca inferior a quatro anos - nem superior, via de regra, a seis. Com risco de incidir no supérfluo, o Miniștério Público lembra que o controle da criação de cursos universitários não se confunde, em absoluto, com o controle do funcionamento individualizado de escolas superiores, tarefa na qual a falibilidade humana tem largo trânsito - e os cultores da ciência do direito o sabem melhor que ninguém.

Se o bom êxito num programa completo de graduação universitária é o pressuposto da capacidade para a adequada execução dos "métodos e técnicas" a que se referem os textos em causa, será possivel afirmar, sem nenhum desdouro para os profissionais da medicina, que a eles lhes falece tal capacidade, porque de outra se fizeram titulares do curso médico. Não haveria como cogitar da competência concorrente, a menos que a graduação em medicina comportasse o inteiro currículo do curso de fisioterapia, ou de terapia ocupacional, alcançando, dessarte, duração próxima dos dez anos. Só um descabido preconceito elitista, por outro lado, levaria a supor que a cena universitária abriga mentes subalternas, precisadas de quatro ou cinco anos para captar aquilo que outros espíritos dominariam mediante trato sumário, ao longo de curso diverso. $\dot{E}$ certo que os programas de graduação diferem uns dos outros, ora em extensão média - quatro, cinco, seis anos - , ora mesmo em grau de abstração ou de complexidade - tenha-se em mira, nesse particular, o paralelo entre a graduação em física nuclear e a graduação em biblioteconomia. Mas não diferem, nem diferirão jamais enquanto o Conselho Federal de Educação se desincumbir, com a costumeira seriedade, de sua importante tarefa - a ponto de que qualquer deles represente mera parcela incidente de qualquer outro, caso no qual a outroga de autonomia, ao primeiro, teria sido clamoroso absurdo. 
manifestação dos órgãos envolvidos no processo legislativo que deu origem às normas atacadas, e da produção de memoriais por ambas as partes.
No tocante ao art. 12 da Lei n: 6.316/75, as informações da Consultoria Jurídica do Ministério do Trabalho bem demonstram que o dispositivo reclama regulamentação, mas não padece de vício algum (folhas 96/97).

Esse artigo de lei, com efeito, exige que as "... empresas cujas finalidades estejam ligadas à fisioterapia ou terapia ocupacional..." se façam registrar nos competentes conselhos regionais. A regra em nada diz respeito aos profissionais da medicina, ou, de resto, a quaisquer profissionais liberais. Ela se volta unicamente para as empresas, ao dizer que estas, quando vinculadas à fisioterapia, ou à terapia ocupacional, devem promover o registro coerente com o vínculo. O texto não diz, aliás, que tal registro há de ser o único, vez que uma empresa pode, acaso, estar ligada a algo mais que uma das especialidades em questão. A compatibilidade entre esse artigo de leie a ordem constitucional está ao largo de toda dúvida.

Ante o exposto, o parecer é por que essa alta Corte declare improcedente, por inteiro, a representação.

Brasília, 30 de abril de 1981.

(a) José Francisco Rezek

Subprocurador-geral da República 


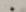

4 